\title{
Writing in the Engineering Design Lab: \\ Integrating Communication Skills into the Engineering Curriculum
}

\author{
D.M. Douglas, C.R. Johnston, D.J. Caswell, M. Eggermont \\ Faculty of Engineering \\ University of Calgary \\ ddouglas@ucalgary.ca
}

\begin{abstract}
The writing process, a process of generating ideas and supporting arguments with information and evidence, parallels the engineering design process. Rhetorical skills, as outlined by Aristotle, emphasize audience and purpose. This emphasis corresponds to the importance of familiarization in the engineering design process. Integrating a communication component into a design course creates an environment where the two disciplines complement each other. Communication assignments teach students how to search out more than one point of view, how to find and assess evidence, how to question, how to uncover assumptions and how to prepare models and predict consequences, all good training for engineering design. Logbooks, oral reports, proposals and team contracts are assignments which integrate communication skills into the engineering curriculum.
\end{abstract}

\section{Introduction}

Over the last decade, many engineering faculties have reintroduced engineering design courses to counteract curricula that "emphasized engineering science and analysis to the point of reductionism at the expense of design and integration" [1]. In part, these courses have been introduced to answer employers' demands for engineering graduates who are not only technically skilled but also able to handle open-ended problems, communicate with clients, work in teams, manage projects and think critically. How are these 'soft' skills developed in an engineering design course?

The continuing debate around teaching communication and critical thinking divides between integrated and addon solutions. Should engineering faculties send students to the English department for technical writing or should they integrate communication and creative thinking into the existing curriculum? Most educators agree that integration increases student motivation for learning and imbeds communication and thinking strategies into disciplinary practice.
The first year engineering design course at the University of Calgary, an interdisciplinary collaboration between art, engineering and communication, focuses on creative problem solving, teamwork and communication. This paper will deal with the links between engineering and communication, particularly in expanding student perception about ways of approaching problems, though obviously the art component of the course is also aimed at broadening students' perceptual abilities.

The 600 students entering the first year design lab work on real world, open-ended problems from the first day of class. They are divided into teams of four to tackle ill-defined engineering problems for real clients. In encountering 'wicked' rather than 'tame' engineering problems, students are pushed beyond their accustomed role of receivers of information and forced into active inquiry $[2,4]$. This creates a teaching environment in which students rely on their own intellectual resources and develop confidence in their own problem solving abilities. It also fosters an environment in which students seek practical design methodology and strategies to successfully communicate their design ideas.

\section{What skills do students learn in communication assignments and how do these skills relate to engineering design?}

\subsection{The Design Process}

We introduce engineering design to first year engineering students as an iterative process called the design trinity. It emphasizes three key aspects of design: familiarization, functionality and testing [3]. We see these elements are at work in every stage of the design process from the initial engagement with the client to determining specifications for the final design. At early stages of the design process, engineers seek to understand the nature of the design problem, the client's expectations and the user's needs. They familiarize themselves with the problem, researching materials, identifying critical functions for performance, testing the assumptions and 
understanding of clients and users. As the design progresses, they design and test at increasingly refined levels. This in turn increases familiarization with the nature of the design problem.

The design process is often presented to undergraduates as a series of staged steps stemming from the initial client statement: problem statement, problem definition, conceptual design, preliminary design, final design. Each of these words is a noun, describing a documentation stage of the design process. It is interesting to note that these words do not describe the process itself, merely the result. From a writer's point of view, nouns are never as powerful as verbs. Describing a process exclusively in terms of nouns misses the actions involved in the process. In contrast, the design trinity, with its emphasis on familiarization, functionality and testing, uses verbs to describe the process. While technically still nouns, they are what linguists call nominalizations, nouns which derive from verbs. Designers familiarize themselves with the problem. Design solutions function in particular ways. Engineers test design solutions for performance.

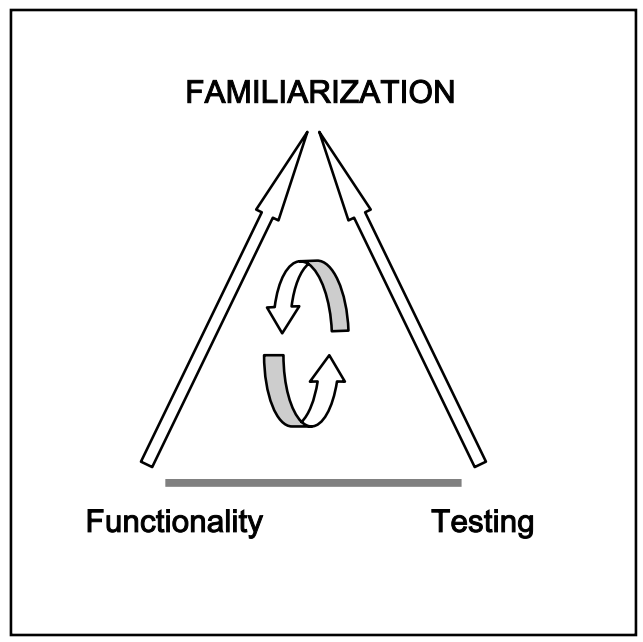

Figure 1. The Design Trinity

The design trinity can be visualized as three points of a continuing design cycle. Familiarization (fact finding and observation) begins the problem solving. Because it is the consistent touchstone of the entire design process, it is at the apex of the design trinity. As the designer continues to define and refine function, and to test for performance to satisfy both clients and users, familiarization increases. Each new level of understanding as the design develops creates a more complete picture of the design context. This continued reorientation to the design problem is the iterative loop imbedded in all design process.

\subsection{The Writing Process}

The writing process was first codified by the Greek philosopher Aristotle in the 5th century B.C.E. The Rhetoric outlines a process of generating ideas, selecting audience appropriate material, and developing and supporting arguments for public oratory. Nearly all writing texts are based on the principles in The Rhetoric. They are sometimes explicitly acknowledged, sometimes not. Key to the writing process as Aristotle describes it is an understanding of the rhetorical situation: Who is the audience? What is the purpose of the document?

Aristotle's emphasis on audience and purpose corresponds to the engineering questions of user and client expectations and needs, and to the functionality of the proposed design. Understanding the rhetorical situation corroborates the engineering idea of familiarization. Stressing the importance of supporting arguments with relevant and credible evidence aligns with the importance of testing and justification in design. The writing process and the design process corroborate one another and make the engineering design lab a particularly responsive environment in which to introduce the basic principles of clear communication.

The writing process requires both generative and analytical thinking. In order to build a successful argument, students must generate ideas (not stopping at the first good point) and then they must learn to select the strongest points to develop. Selection requires analysis or convergent thinking; development requires idea generation or divergent thinking. These repeated patterns of thinking, imbedded in the writing process, parallel the divergent and convergent thinking skill necessary in good engineering design. Students develop multi-logical reasoning strategies in both aspects of the course. 
Table 1.Commonalities Between Writing \& Design

\begin{tabular}{|l|l|l|}
\hline $\begin{array}{l}\text { Writing \& Design } \\
\text { Processes }\end{array}$ & $\begin{array}{l}\text { Types of } \\
\text { Thinking }\end{array}$ & Design Stages \\
\hline $\begin{array}{l}\text { Situation } \\
\text { Divergent } \\
\text { thinking }\end{array}$ & $\begin{array}{l}\text { Fact finding } \\
\text { Researching diverse } \\
\text { views }\end{array}$ \\
\hline Problem Definition & $\begin{array}{l}\text { Convergent } \\
\text { thinking }\end{array}$ & $\begin{array}{l}\text { Analysis of problem to } \\
\text { identify relevant issues/ } \\
\text { criteria } \\
\text { Narrowing problem to } \\
\text { key issues/ criteria }\end{array}$ \\
\hline $\begin{array}{l}\text { Generating } \\
\text { Arguments/ }\end{array}$ & $\begin{array}{l}\text { Divergent } \\
\text { thinking }\end{array}$ & $\begin{array}{l}\text { Idea generation } \\
\text { Brainstorming } \\
\text { Concept mapping }\end{array}$ \\
\hline $\begin{array}{l}\text { Selecting } \\
\text { Evidence/ Design } \\
\text { Ideas }\end{array}$ & $\begin{array}{l}\text { Convergent } \\
\text { Thinking }\end{array}$ & $\begin{array}{l}\text { Analysis, comparison \& } \\
\text { testing of arguments/ } \\
\text { solutions } \\
\text { Judging most } \\
\text { appropriate designs }\end{array}$ \\
\hline Revision & $\begin{array}{l}\text { Implementation } \\
\text { Convergent }\end{array}$ & $\begin{array}{l}\text { Revising document or } \\
\text { design for intended } \\
\text { purpose/ audience/ } \\
\text { client }\end{array}$ \\
\hline thinking
\end{tabular}

\section{What types of communication assignments facilitate the development of 'soft' skills in the engineering design lab?}

The communication assignments in the first year engineering lab are designed to help students work effectively in teams, clarify open-ended and ill-defined problems, develop and justify design solutions and communicate effectively with clients.

\subsection{Team Contract}

Because students work on projects in teams of four, they soon face team related questions such as work distribution, scheduling tasks, group reporting and handling team conflict. One of their early assignments is to develop a team contract which overtly addresses these issues. The first team contract is usually an instructororiented document, answering the questions the instructor has laid out. However, once students find that one team member isn't pulling his or her weight, or leadership conflicts come up, or work is beginning to fall behind, the team contract begins to evolve into a student-oriented document. We encourage students to revise their team contract as the project progresses. It becomes a useful working document and a guide for managing their project.

Early in the term, we schedule a learning style inventory which helps team members to identify their own learning and working preferences and to understand the preferences and styles of others. This assists them in developing reasonable expectations of team members and distributing the workload according to team members' strengths.

\subsection{Logbooks}

All students are required to keep logbooks recording their design ideas. We encourage students to include notes and make connections from other classes, guest lecturers, as well as observations they make both on and off the campus. Coming up with innovative ideas relies on flexible perception and connecting concepts from various sources. The logbooks encourage this kind of incidental learning.

We stress that logbooks are a professional record of all aspects of the design project: meetings, work distribution, research information, project schedules, developing ideas, abandoned ideas, design of tests, results of tests, records of conflict or disagreement. Students put weekly project status reports in their logbooks to keep the design on track and to schedule and record work assigned and date of completion. In the event of team conflict over a grade, we ask to see the team contract and logbooks as evidence to support claims of greater or lesser contributions by certain team members.

\subsection{Oral Reports}

Students make oral progress reports at milestone stages of their design, typically after familiarization with the design problem, after initial testing of a design prototype and after design modifications and testing. Oral reporting forces students to articulate their design ideas and to justify them. Through reports students often see weaknesses in their own process. Oral milestone reports also allow students to compare their design ideas with those of other lab tables in the room. 


\subsection{Proposals}

Students write proposals to present their design solutions to clients. We have found that reports written for actual clients are much stronger than those assigned for no 'real' audience [4]. The proposal is seen by students as an opportunity to pitch their design to a client who just might accept it, rather than as an arbitrary writing assignment. Writing for an actual client motivates students to communicate clearly (concise executive summary, appropriate headings, interpretation of testing results and resultant design modifications etc.). The proposal is an opportunity for students to propose their own ideas, about which they are justifiably proud. When they write for an audience who is interested in the design and its justification, their writing is stronger than when they are assigned reports solely to evaluate writing skill. When the focus is on communicating ideas, not merely demonstrating writing ability, students have a strong incentive to organize material, support claims and edit carefully.

If the proposal is assigned before the end of the project, students have time to revise their designs considering- client/user response and feedback. We have found that because students invest a lot in their designs, they welcome informed and specific suggestions for improvement. Assigning the proposal at the end of a project rather than a week before misses a critical opportunity for students to push their designs to the next stage at a point when they are maximally engaged in the engineering design process.

\subsection{Performance Evaluation}

At the end of term, we assign a self-reflective exercise asking students to consider their progress over the term and to target areas for improvement in the next term. At this point, the end, we usually hear about the importance of writing a good team contract and of paying more attention at the initial stages of the design process. Entering students don't know what they don't know. They leap to solutions too quickly without completely investigating the design problem and constraints. In terms of engineering, they make assumptions about the design problem and neglect the critical familiarization stage. In terms of teamwork, they assume all team members see the problem and team dynamics as they do and they can't foresee potential areas of conflict. The final memo encourages students to articulate what they've learned about the design process and about teamwork and to identify those areas in which they are personally weakest.

\section{What are the benefits of explicitly combining communication and engineering design in the same course?}

Critical to all good design, in any discipline, is a firm understanding of the design situation. What does the designed object/ document/ process need to do? Who will use it? When? How often? Why? Without a solid understanding of the design context, no good design can emerge. The writing process makes these questions explicit.

Engineering is creative problem solving. It is dependent upon both engineering knowledge and thinking skill. Knowledge of math, physics, mechanics and programming must be complemented by the ability to think creatively and critically. Most engineering problems are not well defined; successful engineers must learn to work in an environment where there are no right answers, only defensible ones. The writing process, a process of supporting arguments with evidence and support, provides a good training ground for justifying and defending engineering ideas.

Engineering solutions do not result from technical information alone, nor can they be achieved by following a rigid set of steps. In order to arrive at innovative solutions for design problems, designers have to use informed intuition. The 'informed' part of innovation comes from technical understanding as well as the ability to question and test: the familiarization stage of the design trinity. Communication assignments in the design lab teach students how to search out more than one point of view, how to find and assess evidence, how to question, how to uncover assumptions and how to prepare models and predict consequences.

Engineering principles are made meaningful by interpretation and application. Students apply technical knowledge learned in other courses to their design solutions in the engineering design lab. Communication assignments such as oral reports and proposals force students to articulate the ways in which they have integrated engineering principles into their designs and to see how other students have employed engineering knowledge. They also provide valuable feedback to developing design ideas. Fellow students question and critique design ideas, generating important questions for design revision.

Communication assignments are particularly beneficial for large classes. We post good and excellent examples (anonymously) of reports, team contracts and proposals, both electronically and in display cabinets outside the lab. Our marking scheme consists of three categories: good, excellent and 're-do' [3]. Initially, many students need to reconsider their work in order to raise it to an acceptable standard. Posted examples, with instructor remarks 
pointing out areas of strength, provide students with models for revision. The posted examples allow instructors to address such questions as the integration of engineering principles, appropriate design of testing, and solid justification of design ideas.

\section{What are the benefits of interdisciplinarity in the design lab?}

Every discipline works within a defined area built on knowledge assumptions and patterns of inquiry central to the discipline. Combining several disciplines within a single course or program expands the space of inquiry by examining the course content from several perspectives.

Interdisciplinary courses bring together faculty members working on different knowledge planes. These planes intersect, offering several views or perceptual frameworks in which to develop the course. This has the advantage of broadening the appeal of the course. Not only does enrolment increase, but the program is more likely to retain students with a wide range of interests. One of the goals at the University of Calgary was to retain creative students who were leaving the faculty because the program offered them no scope for the breadth of their interests.

Bringing several disciplines together, (in our case, art, engineering and communication) has allowed us to illustrate that design is not a staged process but a series of spontaneous ignitions. We are able to put the emphasis on the environment or atmosphere of design, not on the process, and the design lab has become a place where innovation happens.

\section{References}

[1] James G. Harris., "Journal of Engineering Education Round Table: Reflections on the Grinter Report", Journal of Engineering Education, Jan. 1994, pp. 69-94

[2] H.W.J. Rittel, "Impressions of Architecture 130: Notes and Observations of Prof. Horst W.J. Rittel's Classic Design Methods Course at Berkeley as taught circa-1969-1971" Design Methods, Theories, Research, Education and Practice, 1996 Vol 29 no. 1 to vol. 32 no. 4

[3] D.J. Caswell, C.R. Johnston, D.M.Douglas and M. Eggermont, "Fundamentals of a First-Year Engineering Design and Communication Course: Familiarization, Functionality and Testing." Proceedings of the 2004 American Society for Engineering Education Annual Conference \& Exposition, June 2004.

[4] D.M. Douglas, C.R. Johnston, D.J. Caswell, M. Eggermont, "Writing in the Engineering Design Lab: How Problem Based Learning provides a Context for Student Writing", Proceedings of the 2004 American Society for Engineering Education Annual Conference \& Exposition, June 2004. 